\title{
Characterization of Erwinia amylovora bacteriophages isolated in Belarus
}

Besarab N.V. ${ }^{1}$, Golomidova A.K. ${ }^{2}$, Kulikov E.E. ${ }^{2}$, Letarov A.V. ${ }^{2}$, Lagonenko A.L. ${ }^{1}$, Evtushenkov A.N. ${ }^{1}$

${ }^{1}$ Faculty of Biology, Belarusian State University, Minsk, Belarus; ${ }^{2}$ Federal State Institution «Federal Research Centre «Fundamentals of Biotechnology» of the Russian Academy of Sciences», Winogradsky Institute of Microbiology, Moscow, Russia

E-mail: natal-vasilna@rambler.ru

Key message. Erwinia amylovora bacteriophages from the Myoviridae and Podoviridae families were isolated in Belarus. The E. amylovora growth rate was 1.6-7.8 times decreased in the presence of investigated bacteriophages.

Keywords: Erwinia amylovora, bacteriophages, fire blight, Podoviridae, Myoviridae

Control of phytopathogenic bacteria Erwinia amylovora, the causative agent of fire blight, could be conducted using specific bacteriophages, able to suppress the growth of phytopathogen without the use of antibiotics. Such phages can be isolated from natural sources and characterized by various methods before use as a biocontrol agent. This work was aimed to isolate from natural sources and characterize the E. amylovora bacteriophages as the potential biocontrol agent to combat the phytopathogen. Isolation of bacteriophages from soil samples was performed using enrichment culture method and bacterial strain E. amylovora $1 / 79 \mathrm{Sm}$ was used for bacteriophage propagation. The analysis of the morphology of bacteriophage particles was carried out employing the JEOL JEM-2100 transmission electron microscope (TEM), by using negative staining with $2 \%$ uranyl acetate. Bacteriophage protein profiles were analyzed by SDS-PAGE technique in a $10 \%$ polyacrylamide gel. The dynamics of bacterial culture growth after infection with bacteriophages were studied during an incubation in LB broth in 96-well plates at a temperature of $28{ }^{\circ} \mathrm{C}$ using a Thermo Scientific Multiskan FC photometer. In the present work, E. amylovora bacteriophages were isolated from soil samples on the territory of the Minsk and Grodno regions of Belarus. Electron microscopic studies indicated that bacteriophages belong to two tailed phages families - Myoviridae (Hena2, Pixel, Dichka, Roscha1, VyarbaS) and Podoviridae (Loshitsa2, Fleur, Stepyanka, Micant). The particle sizes of bacteriophages

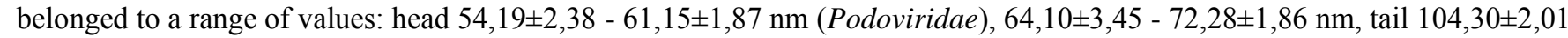
- 107,08 $\pm 2,5 \mathrm{~nm}$ (Myoviridae). SDS-PAGE analysis of phage proteins indicated similarity of protein profiles among bacteriophages of these groups. The $\mathrm{OD}_{620 \mathrm{~nm}}$ measurement of the bacterial culture during 5 hours of incubation after infection with bacteriophages $\left(10^{6}\right.$ and $10^{7} \mathrm{PFU} / \mathrm{ml}$ phage titer) indicated a 1.6-7.8 times decrease of the bacterial culture growth rate. The growth rate was determined by the slope of the linear function of the bacterial culture growth as an approximation model. A more significant effect on the bacterial growth rate was exerted by infection with the investigated bacteriophages of the Podoviridae family - a 6,1 (Fleur, Loshitsa2), 7,8 (Stepyanka) times decrease of the growth rate. This study identified new Myoviridae and Podoviridae bacteriophages capable of reducing in vitro growth of E. amylovora. This data is of great importance to guide the discovery of new possible plant-protection product to be used in the management of fire blight. 